\title{
NOTAS SOBRE A REDEFINIÇÃO DA IDENTIDADE E DAS POLÍTICAS PÚBLICAS DE EDUUCAÇÃO DE JOVENS E ADULTOS NO BRASIL*
}

\author{
Maria Clara Di Pierro*
}

\begin{abstract}
RESUMO: $\mathrm{O}$ artigo visa identificar temas e processos emergentes do campo das políticas públicas de educação de jovens e adultos no Brasil. Aborda inicialmente o processo de redefinição da identidade da educação de jovens e adultos desencadeado pelo reconhecimento da diversidade sociocultural dos educandos, bem como pelo embate entre o paradigma compensatório e a concepção de educação continuada ao longo da vida. Trata, a seguir, dos desafios e impasses das políticas públicas para superar a posição marginal ocupada pela educação de jovens e adultos na reforma educacional da segunda metade da década de 1990. Ao final, sugere que os principais desafios a serem respondidos pelas políticas públicas no presente são os que emergem da agenda de diálogo e conflito entre os movimento em prol da educação de jovens e adultos e os governos, tais como a articulação entre alfabetização e escolarização, as estratégias de financiamento público e colaboração entre as instâncias de governo, bem como a formação e profissionalização dos educadores.

Palavras-chave: Políticas educacionais. Educação de jovens e adultos. Movimentos sociais e educação.
\end{abstract}

\section{ANNOTATIONS ON THE REDEFINITION OF THE IDENTITY} AND THE PUBLIC POLICIES FOR YOUTH AND ADULT EDUCATION IN BRAZIL ABSTRACT: The aim of this paper is to identify emerging themes and processes in the area of public policies for youth and adult edu-

\footnotetext{
* Agradeço ao professor Leôncio José Gomes Soares, da Faculdade de Educação da Universidade Federal de Minas Gerais (UFMG), pela colaboração na pauta, indicação de bibliografia e comentários ao texto.

** Doutora em educação e professora da Faculdade de Educação da Universidade de São Paulo (USP).E-mail: mcpierro@uol.com.br
} 
Notas sobre a redefinição da identidade e das políticas públicas de educação...

cation. This paper first explores the process that redefined the identity of and the public policies for youth and adult education in Brazil, resulting from both the recognition of the learners' sociocultural diversity and the conflict between the compensatory paradigm and the concept of continuing education throughout life. It then discusses the challenges and conflicts of the public policies to overcome the marginal position assigned to youth and adults in the educational reform that took place in the 1990. It finally suggests that the main current challenges to be faced by the public policies in this field emerge from the dialogue agenda and the conflict between the movement favoring youth and adult education and the Government. The latter include, among others, the articulation between literacy and schooling, the public financing strategies, the collaboration between the different Government levels, and teacher training and professionalization.

Key words: Educational policies; youth and adult education; social movements and education

\section{Apresentação}

E

ste artigo procura identificar temas emergentes e mapear as principais polêmicas relacionadas às políticas públicas de educação de jovens e adultos no Brasil neste início de terceiro milênio, tomando por base, de um lado, os resultados de pesquisas sobre o assunto e, de outro, as pautas prioritárias da interlocução entre as redes e organizações da sociedade civil e as instâncias governamentais neste campo de ação educativa.

A primeira parte aborda o movimento inconcluso de redefinição da identidade da educação de jovens e adultos no Brasil desencadeado pela transição de paradigmas político-pedagógicos e pela percepção da diversidade sociocultural dos sujeitos de aprendizagem. A segunda parte é dedicada aos desafios e impasses das políticas públicas para superar a posição marginal ocupada pela educação de jovens e adultos na reforma educacional realizada na segunda metade da década de 1990.

A educação de jovens e adultos: um campo em redefinição

\section{Transição de paradigmas}

Embora a história da educação brasileira registre numerosas e criativas experiências de educação não-formal, envolvendo práticas de anima- 
ção cultural, formação política, qualificação para o trabalho e para a geração de renda, os desafios da alfabetização e elevação de escolaridade tendem a ocupar o centro do debate público atual a respeito da educação de jovens e adultos no Brasil, relegando a um plano secundário outras dimensões igualmente relevantes da educação popular. A prioridade conferida à escolarização pode ser atribuída ao fato da Constituição Federal de 1988 assegurar o ensino fundamental público e gratuito em qualquer idade, inscrevendo a educação de jovens e adultos no rol dos direitos da cidadania.

Ao final dos anos 40 do século passado foram implementadas as primeiras políticas públicas nacionais de educação escolar para adultos, que disseminaram pelo território brasileiro campanhas de alfabetização. No início da década de 1960, movimentos de educação e cultura popular ligados a organizações sociais, à Igreja Católica e a governos desenvolveram experiências de alfabetização de adultos orientadas a conscientizar os participantes de seus direitos, analisar criticamente a realidade e nela intervir para transformar as estruturas sociais injustas. Diretriz totalmente contrária teve o Movimento Brasileiro de Alfabetização (MOBRAL) da década de 1970, conduzido pelo regime militar no sentido de sua legitimação.

Nesse mesmo período, em que o sistema educacional foi direcionado a atender às necessidades de recursos humanos demandados do modelo econômico concentrador de riqueza, a escolarização básica para jovens e adultos adquiriu institucionalidade nas redes de ensino: a Lei 5.692 de 1971 reformou o ensino de $1^{\circ}$ e $2^{\circ}$ graus e regulamentou o ensino supletivo, conferindo à suplência a função de repor escolaridade não realizada na infância e adolescência, então consideradas os ciclos da vida mais adequados à aprendizagem.

Aprovada em plena ditadura militar, a "doutrina do ensino supletivo" (como a denominaram seus formuladores) não incorporou as ricas contribuições que os movimentos de educação e cultura popular do início da década de 1960 legaram à educação de adultos (difundidas em todo o mundo pela obra de Paulo Freire). Ao contrário, atendeu ao apelo modernizador da educação a distância e aderiu aos preceitos tecnicistas da individualização da aprendizagem e instrução programada, que fundamentaram a difusão das modalidades de educação não-presencial em centros de estudos supletivos e telecursos, que se somaram aos cursos presenciais na configuração de um subsistema de ensino supletivo em 
Notas sobre a redefinição da identidade e das políticas públicas de educação...

expansão. A ampliação da escolaridade obrigatória de quatro para oito anos de estudos, por sua vez, teve reflexos nas exigências de certificação do mercado de trabalho, o que ampliou substancialmente a procura pelos exames supletivos.

Mais de três décadas depois, e mesmo após a promulgação em 1996 da nova Lei de Diretrizes e Bases da Educação, n. 9.394, a cultura escolar brasileira ainda encontra-se impregnada pela concepção compensatória de educação de jovens e adultos que inspirou o ensino supletivo, visto como instrumento de reposição de estudos não realizados na infância ou adolescência. Ao focalizar a escolaridade não realizada ou interrompida no passado, o paradigma compensatório acabou por enclausurar a escola para jovens e adultos nas rígidas referências curriculares, metodológicas, de tempo e espaço da escola de crianças e adolescentes, interpondo obstáculos à flexibilização da organização escolar necessária ao atendimento das especificidades desse grupo sociocultural. Ao dirigir o olhar para a falta de experiência e conhecimento escolar dos jovens e adultos, a concepção compensatória nutre visões preconceituosas que subestimam os alunos, dificulta que os professores valorizem a cultura popular e reconheçam os conhecimentos adquiridos pelos educandos no convívio social e no trabalho.

Não se pode, porém, atribuir apenas à estreiteza pedagógica do paradigma compensatório os escassos resultados qualitativos alcançados pelo ensino supletivo, para os quais também contribuíram a crônica escassez de recursos financeiros e a falta de preparo específico dos professores, mazelas que atingiram o conjunto do ensino público em expansão naquele período, mas que afetaram de modo mais agudo as modalidades de menor prestígio, como a educação de jovens e adultos.

O fim do regime militar e a retomada das eleições diretas nas capitais em meados dos anos de 1980 criaram o ambiente político-cultural favorável para que os sistemas de ensino público começassem a romper com o paradigma compensatório do ensino supletivo e, recuperando o legado dos movimentos de educação e cultura popular, desenvolvessem experiências inovadoras de alfabetização e escolarização de jovens e adultos. De fato, algumas das iniciativas mais bem sucedidas do período da redemocratização foram conduzidas por governos locais, em parceria com organizações e movimentos sociais, ${ }^{1}$ que emergiram na cena política e impulsionaram o reconhecimento dos direitos sociais na Constituição Fede- 
ral de 1988, dentre os quais os dos jovens e adultos ao ensino público gratuito.

Esse movimento de renovação pedagógica, entretanto, não repercutiu senão de modo tênue nas redes estaduais de ensino, que continuam apegadas ao paradigma compensatório e, apesar do processo de municipalização iniciado nos anos de 1990, ainda registram a maior parte da matrícula na educação escolar de jovens e adultos, respondendo também pela realização dos exames e pela manutenção da maioria dos centros de estudos supletivos.

Quando, em 1997, a V Conferência Internacional de Educação de Adultos realizada em Hamburgo proclamou o direito de todos à educação continuada ao longo da vida, ainda não havia, no Brasil, consenso em torno desse paradigma. Ainda que lentamente, porém, a transição de referências vem sendo impulsionada pelo resgate da contribuição da educação popular, ao lado de um conjunto de mudanças no pensamento pedagógico e nas relações entre educação e trabalho na sociedade contemporânea. A psicologia do desenvolvimento humano já não sustenta a idéia de que exista uma idade apropriada ${ }^{2}$ para aprender: as pesquisas demonstram que a aprendizagem ocorre em qualquer idade, ainda que a pertinência a determinados grupos socioculturais ou etários possa estar relacionada à variância nas funções, características e estilos cognitivos (Oliveira, 1999). Também já não subsiste a suposta correspondência entre etapas do ciclo vital, processos de formação e engajamento na produção, pois diante das rápidas mudanças no mundo do trabalho, da ciência e da técnica, os conhecimentos adquiridos na escolarização realizada na infância e juventude não são suficientes para ancorar toda uma vida profissional e de participação sociocultural na idade adulta, impondo-se a educação permanente. A necessidade da aprendizagem ao longo da vida se amplia em virtude também da elevação da expectativa de vida das populaçôes e da velocidade das mudanças culturais, que aprofundam as distâncias entre as gerações, as quais a educação de jovens e adultos pode ajudar a reduzir. ${ }^{3}$

Frente ao mundo inter-relacionado, desigual e inseguro do presente, o novo paradigma da educação de jovens e adultos sugere que a aprendizagem ao longo da vida não só é um fator de desenvolvimento pessoal e um direito de cidadania (e, portanto, uma responsabilidade coletiva), mas também uma condição de participação dos indivíduos na constru- 
Notas sobre a redefinição da identidade e das políticas públicas de educação...

ção de sociedades mais tolerantes, solidárias, justas, democráticas, pacíficas, prósperas e sustentáveis.

A educação capaz de responder a esse desafio não é aquela voltada para as carências e o passado (tal qual a tradição do ensino supletivo), mas aquela que, reconhecendo nos jovens e adultos sujeitos plenos de direito e de cultura, pergunta quais são suas necessidades de aprendizagem no presente, para que possam transformá-lo coletivamente.

\section{A descoberta da diversidade}

Em um país em que o acesso à educação é seletivo, guardando simetria com as profundas desigualdades geográficas e socioeconômicas, como é o caso do Brasil, ${ }^{4}$ a identidade político pedagógica da educação de jovens e adultos não foi construída com referência às características psicológicas ou cognitivas das etapas do ciclo de vida (juventude, maturidade, velhice), mas sim em torno de uma representação social enraizada, de um lado, no estigma que recai sobre os analfabetos nas sociedades letradas e, de outro, em uma relativa homogeneidade sociocultural dos educandos conferida pela condição de camponeses ou migrantes rurais (ou sua descendência) e trabalhadores de baixa qualificação pertencentes a estratos de escassos rendimentos.

Analisando as características dos jovens e adultos enquanto sujeitos de aprendizagem desde o prisma da psicologia, Oliveira (1999) ponderou que a relativa homogeneidade social dos estudantes (a maioria dos quais são migrantes rurais adultos de baixa renda que, no meio urbano, desempenham ocupações não-qualificadas, ou jovens urbanos pobres, ambos excluídos da escola) não sustenta abstrações universalistas, assinalando que a educação de jovens e adultos remete primordialmente a uma questão de especificidade cultural, uma vez que - à luz da perspectiva histórico-cultural - as práticas culturais são constitutivas do psiquismo e a heterogeneidade é resultado necessário dessa construção.

No entanto, os balanços da literatura sobre a educação de jovens e adultos no Brasil mencionam que, até os anos de 1990, a maior parte das pesquisas sobre o tema tendeu a homogeneizar os sujeitos de aprendizagem, abstraindo sua diversidade e diluindo suas identidades singulares - de classe, geracionais, de gênero, étnicas, culturais ou territoriais sob a condição e o rótulo genérico de "alunos" (Haddad, 1987, 2002). 
Desde os anos de 1980, a reconstrução do conceito de sociedade civil como instância dotada de capacidade de resistência e iniciativa, construtora de direitos de cidadania no espaço público, favoreceu a constituição, na pesquisa educacional brasileira, de um campo de estudos sobre os movimentos sociais e a educação, que conferiu visibilidade às identidades coletivas emergentes e abordou tanto os impactos sobre o ensino público quanto o caráter educativo das lutas e a ressocialização dos sujeitos no seu interior (Sposito, 2000; Gohn, 2004). Foi nesse contexto que o surgimento de um "novo sindicalismo" e o interesse que ele gerou para a sociologia dos movimentos sociais conferiu visibilidade à condição de classe dos educandos jovens e adultos, designados a partir de então como "alunos trabalhadores", o que colocou em foco as relações de cooperação e conflito entre educação e trabalho. Os estudos sobre o tema concentram suas análises na evasão e fracasso escolar, ponderando a inadequação da organização escolar e dos projetos pedagógicos do ensino noturno para atender às expectativas e características dos estudantes trabalhadores (Haddad, 1987, 2002; Corrochano \& Nakano, 2002).

Nos anos mais recentes, a emergência de movimentos que reivindicam o reconhecimento político e cultural de identidades sociais singulares (mulheres, negros, jovens, indígenas, sem terra), ao lado da difusão do pensamento de autores orientados ao interculturalismo e/ou vinculados ao "paradigma da identidade", 5 favoreceu o reconhecimento da diversidade dos sujeitos da educação de jovens e adultos. Em princípio, sobressai a percepção da "juvenilização" do alunado da educação de jovens e adultos, ${ }^{6}$ mas também começam a surgir os recortes de gênero ${ }^{7}$ e a especificidade do campo, ${ }^{8}$ sendo raros e recentes os estudos que abordam a condição étnico-racial (Passos, 2004), mesmo quando os diagnósticos indicam que a população negra é maioria dentre os jovens e adultos analfabetos e com baixa escolaridade. Ainda mais notável é a escassez de conhecimento sobre as pessoas com necessidades educativas especiais, assim como sobre as identidades e práticas religiosas dos jovens e adultos inseridos em processos de escolarização. ${ }^{9}$

\section{Desafios das políticas públicas de educação de jovens e adultos}

La educación de adultos en el Sur ha estado siempre atrapada entre recursos y atención tremendamente pobres, por un lado, y expectativas tremendamente ambiciosas, por el otro: autoestima, empoderamiento, construcción 
Notas sobre a redefinição da identidade e das políticas públicas de educação...

de ciudadanía, organización comunitaria, habilidades para el trabajo, generación de ingresos, e incluso alivio de la pobreza. Si los gobiernos y la comunidad internacional esperan que la alfabetización y la educación de adultos tengan los impactos deseados sobre la vida de las personas, las famílias y las comunidades, entonces debemos invertir más - no menos (...). Pero, además, esa inversión debe ir acompañada de reformas econômicas y sociales significativas y más amplias. (Torres, 2003, p. 24)

O período de transição do milênio foi marcado, em todo o mundo, pelo crescimento das aspirações e da participação dos jovens e adultos em programas educacionais. Dentre as motivaçóes para a busca de maiores níveis de escolarização após a infância e adolescência, destacamse as múltiplas necessidades de conhecimento ligadas ao acesso aos meios de informação e comunicação, à afirmação de identidades singulares em sociedades complexas e multiculturais, assim como às crescentes exigências de qualificação de um mundo do trabalho cada vez mais competitivo e excludente. No caso brasileiro, esses fatores favoreceram a expressão de parcela da extensa demanda potencial acumulada ao longo de uma história de negação de direitos e limitado acesso à educação escolar, que legou ao presente grandes contingentes de jovens e adultos analfabetos, com reduzida escolaridade e escasso preparo profissional. ${ }^{10}$

Embora todos os grupos etários tenham, na conjuntura atual, necessidades de aprendizagem incrementadas, a maior parte das pessoas que busca no sistema educacional brasileiro oportunidades de estudos acelerados em horário noturno (as características da educação básica de jovens e adultos mais claramente percebidas) são adolescentes e jovens pobres que, após realizar uma trajetória escolar descontínua, marcada por insucessos e desistências, retornam à escola em busca de credenciais escolares e de espaços de aprendizagem, sociabilidade e expressão cultural. O perfil marcadamente juvenil que a educação escolar de adultos adquiriu no Brasil na última década deve-se à combinação de fatores ligados ao mercado de trabalho (exigência de certificação escolar) e ao sistema educativo (elevada defasagem na relação idade/série), potencializados pela redução da idade mínima permitida pela Lei de Diretrizes e Bases da Educação Nacional (LDB) de 1996 para a freqüência a essa modalidade de educação básica.

As análises sobre as políticas públicas de educação de jovens e adultos, que deveriam responder a essas aspirações e demandas, destacam os impasses gerados por dois impulsos contraditórios desencadeados no pe- 
ríodo da redemocratização das instituições políticas do país. De um lado, formou-se um amplo consenso em favor da alfabetização e da educação básica como esteios da participação cidadã na sociedade democrática e da qualificação profissional para um mundo do trabalho em transformação, o que se refletiu no alargamento dos direitos educativos dos jovens e adultos consagrados na legislação. Por outro lado, a educação de jovens e adultos ocupou lugar marginal na reforma educacional da segunda metade dos anos de 1990, implementada sob o condicionamento das prescrições neoliberais de reforma do Estado e restrição ao gasto público, e orientada pelas diretrizes de desconcentração, focalização e redefinição das atribuições dos setores público e privado. ${ }^{11} \mathrm{Na}$ zona de conflito formada por esses impulsos conflitantes emergiu o movimento dos fóruns de educação de jovens e adultos, conformando espaços públicos de expressão e legitimação de reivindicações, diálogo e negociação.

\section{A focalização da política de educação básica}

Com base no argumento (bastante controverso) de que a educação básica de jovens e adultos oferece uma relação custo-benefício menos favorável que a educação primária de crianças, prevaleceu na reforma educacional brasileira da década de 1990 a orientação de focalização dos recursos públicos no ensino fundamental de crianças e adolescentes, visto como estratégia de prevenção do analfabetismo. ${ }^{12} \mathrm{O}$ principal mecanismo utilizado para operacionalizar a focalização é bastante conhecido - o Fundo de Valorização do Ensino Fundamental (FUNDEF), do qual as matrículas do ensino de jovens e adultos foram expurgadas por imposição de um veto do então presidente da República Fernando Henrique Cardoso. Rompeu-se, assim, o princípio da universalidade inerente ao direito humano à educação: embora as leis maiores assegurem a todos o acesso e a progressão na educação básica pública, gratuita e de qualidade, a focalização de recursos para a educação escolar na faixa etária de 7 a 14 anos suprimiu os meios para que as instâncias administrativas do Estado cumpram adequadamente seu dever na provisão de ensino fundamental aos jovens e adultos.

Nesse contexto, as demandas e necessidades educativas dos jovens e adultos, quando consideradas, foram abordadas com políticas marginais, de caráter emergencial e transitório, subsidiárias a programas de alívio da pobreza. Embora perspectivas distintas possam ter se desenvolvido em al- 
Notas sobre a redefinição da identidade e das políticas públicas de educação...

guns estados e municípios, essa foi a tônica das iniciativas do governo federal durante a gestão 1996-2002, que desenhou os programas Alfabetização Solidária, Recomeço e de Educação na Reforma Agrária. ${ }^{13}$

Estados e municípios reagiram a essa conjuntura de modos variados. A ampliação, redução ou manutenção dos serviços de educação de jovens e adultos dependeu da capacidade financeira de cada Unidade da Federação, da vontade política dos respectivos governantes, da demanda e pressão social da população local em defesa desse direito. Em grande parte dos casos, a exclusão da educação de jovens e adultos do FUNDEF criou empecilho à expansão das matrículas, sem contudo interromper o crescimento do atendimento escolar às pessoas com mais de 14 anos, como demonstram os censos educacionais (tabelas 1 e 2).

Não há pesquisa abrangente sobre o tema, mas estudos de casos específicos demonstram que estados e municípios recorreram a duas estratégias para atender à crescente demanda por educação de jovens e adultos em um contexto adverso de marginalização da modalidade e escassez de recursos. O expediente mais freqüente foi o falseamento das estatísticas, declarando-se no censo escolar as matrículas na educação de jovens e adultos como ensino regular em classes de aceleração para estudantes com defasagem série-idade, modalidade esta passível de captação de recursos dos fundos. Um dos problemas advindos da adesão a esse expediente é a descaracterização da educação de jovens e adultos como modalidade que requer norma própria, projeto político-pedagógico específico e adequada formação de educadores. Outra estratégia largamente difundida foi o estabelecimento de parcerias com organizações sociais para a execução direta dos serviços educativos para jovens e adultos. Embora a maior parte dessas parcerias tenham origem em um movimento político de voluntariado, participação e educação popular (como é o caso dos Movimentos de Alfabetização - MOVA), as motivaçóes altruístas das organizações sociais foram convergentes ao intuito dos governos de baratear os custos dos serviços de educação de jovens e adultos. Os riscos dessa inesperada convergência são de três ordens: a delegação de responsabilidades públicas à sociedade civil organizada; a tendência regressiva de desconstituição dos direitos educativos dos jovens e adultos, e sua conversão em objeto da filantropia privada; a institucionalização da precariedade das instalações físicas, recursos humanos e pedagógicos, que caracteriza a improvisação da escolarização promovida pelas organizações e movimentos sociais. 
O principal resultado da diretriz de focalização do investimento público no ensino fundamental de crianças e adolescentes é a segmentação do acesso dos jovens e adultos aos serviços educativos, o que representa a ruptura do princípio de universalidade e a desconstituição de um direito duramente conquistado.

\section{Centralização e descentralização da responsabilidade governamental}

Embora no Brasil a provisão pública do ensino elementar aos jovens e adultos sempre tenha sido desconcentrada e assumida pelos estados, municípios e organizações sociais, ao longo da segunda metade do século XX a União desempenhou um papel de coordenação política, tomando iniciativas e induzindo o comportamento dos demais níveis de governo mediante a modelagem e o financiamento de campanhas de alfabetização ou projetos de formação de professores leigos, cursos a distância, centros de estudos ou exames supletivos.

No início da década de 1990, a União recuou nessa função de coordenação das políticas e, após a súbita extinção da Fundação Educar, ${ }^{14}$ a responsabilidade pelo custeio e provisão da alfabetização de jovens e adultos recaiu sobre os municípios. Até 2004, porém, os estados continuaram sendo os principais mantenedores da escolarização de jovens e adultos, respondendo sobretudo pelo alunado das séries finais do ensino fundamental e pela totalidade do ensino médio.

Quando, em 1996, a Presidência da República vetou o cômputo das matrículas no ensino fundamental de jovens e adultos nos cálculos do FUNDEF, estados e municípios foram desestimulados a ampliar a oferta dessa modalidade de ensino. As estatísticas disponíveis para esse período não são de todo confiáveis, mas oferecem evidências de que a demanda social se impôs às condiçôes adversas de financiamento do setor público, pois a matrícula pública no ensino fundamental de jovens e adultos teve um aumento de $220 \%$ entre 1998 e 2004 . Nesse período, observou-se também um processo de descentralização, pelo qual os municípios incrementaram sua participação na oferta de ensino fundamental, absorvendo parte do atendimento anteriormente realizado pelos estados, enquanto estes concentraram sua participação no ensino médio, etapa da educação básica que, em 2004, teve um incremento de matrícula de $18 \%$. 
Notas sobre a redefinição da identidade e das políticas públicas de educação...

\section{Tabela 1}

(Brasil: Evolução das matrículas na educação básica de jovens e adultos por Dependência Administrativa - 2000/2004)

\begin{tabular}{|l|c|c|c|c|c|c|c|c|c|}
\hline Ano & Total & Federal & $\%$ & Estadual & $\%$ & Municipal & $\%$ & Privada & $\%$ \\
\hline 2000 & 3.410 .830 & 11.573 & 0,34 & 2.018 .504 & 59,18 & 1.005 .218 & 29,47 & 375.535 & 11,01 \\
\hline 2001 & 3.777 .989 & 5.490 & 0,15 & 2.004 .321 & 53,05 & 1.416 .117 & 37,48 & 352.061 & 9,32 \\
\hline 2002 & 3.779 .593 & 3.327 & 0,09 & 1.759 .487 & 46,55 & 1.700 .862 & 45,00 & 315.917 & 8,36 \\
\hline 2003 & 4.403 .436 & 1.284 & 0,03 & 2.166 .915 & 49,21 & 1.953 .280 & 44,36 & 281.957 & 6,40 \\
\hline 2004 & 4.577 .268 & 697 & 0,01 & 2.305 .344 & 50,36 & 2.025 .617 & 44,25 & 245.610 & 5,36 \\
\hline
\end{tabular}

Fonte: MEC/INEP/SEEC

\section{Tabela 2}

(Brasil: Evolução da matrícula inicial no ensino fundamental de jovens e adultos por Dependência Administrativa - 2001/2004)

\begin{tabular}{|l|c|c|c|c|c|c|c|c|c|}
\hline Ano & Total & Federal & $\%$ & Estadual & $\%$ & Municipal & $\%$ & Particular & $\%$ \\
\hline 2001 & 3.818 .925 & 5.490 & 0,1 & 2.034 .515 & 53,3 & 1.427 .628 & 37,4 & 351.292 & 9,2 \\
\hline 2002 & 2.905 .592 & 2.779 & 0,1 & 1.124 .711 & 38,7 & 1.674 .998 & 57,6 & 103.104 & 3,5 \\
\hline 2003 & 3.315 .887 & 909 & 0,0 & 1.387 .505 & 41,8 & 1.846 .964 & 55,7 & 80.509 & 2,4 \\
\hline 2004 & 3.419 .675 & 381 & 0,0 & 1.354 .808 & 39,6 & 1.987 .723 & 58,1 & 76.736 & 2,2 \\
\hline
\end{tabular}

Fonte: MEC-INEP

A descentralização é tema controverso: os que a defendem sustentam que ela favorece a democratização e a qualidade da educação porque potencializa a participação social nas instâncias locais de poder; os que a criticam apontam o risco de aprofundamento das desigualdades educativas preexistentes entre as zonas geográficas do país. O princípio legal da colaboração entre as esferas de governo a todos unifica, mas as propostas para sua operacionalização - como o FUNDEF - não reúnem consenso. 
Os analistas mais críticos ponderam que, se resultou em avanço na inclusão de crianças e adolescentes ao sistema educativo, o Fundo teve reduzido efeito redistributivo, não obteve os resultados esperados na melhoria da qualidade do ensino e, além de não responder à previsível expansão da demanda pelo ensino médio, deixou a descoberto o financiamento da educação infantil e o ensino fundamental de jovens e adultos. A tentativa de transpor esses obstáculos com a criação de um novo Fundo, que abarca toda a educação básica - o FUNDEB, colide, de um lado, com a política macroeconômica (que continua a priorizar o equilíbrio fiscal em detrimento do financiamento das políticas sociais) e, de outro, gera conflitos de interesse entre os estados e municípios quanto ao investimento nos níveis e modalidades de ensino de respectiva responsabilidade, como o ensino médio e a educação infantil. No estreito espaço de manobra e negociação que resta, há o risco de que a educação de jovens e adultos seja, mais uma vez, colocada em segundo plano.

De fato, nas simulações de regulamentação do FUNDEB que subsidiam as negociações entre representantes dos governos federal, estaduais e municipais, cogita-se atribuir às matrículas na educação de jovens e adultos valores menores que aqueles concedidos a outras modalidades, com o argumento de que um tratamento isonômico geraria estímulos à expansão da matrícula em níveis que colocariam em risco a própria viabilidade do Fundo. As redes que se articulam para a promoção da educação de jovens e adultos rejeitam enfaticamente esse tratamento diferenciado. Uma possibilidade de saída para o impasse seria a fixação de metas de expansão progressiva da matrícula na educação de jovens e adultos, o que poderia evitar o risco mencionado sem, contudo, gerar um tratamento diferenciado, ética e juridicamente inaceitável.

\section{As políticas da União para a educação de jovens e adultos}

$\mathrm{Na}$ experiência brasileira recente de gestão da educação básica de jovens e adultos, a desconcentração do financiamento e provisão do ensino vem se realizando com a manutenção do histórico papel indutor da União, que preservou um conjunto de instrumentos de regulação e controle, com destaque para as transferências de verbas condicionadas à adesão a programas e projetos previamente modelados.

Durante os oito anos da presidência de Fernando Henrique Cardoso, o governo federal conferiu lugar marginal à educação básica de jo- 
Notas sobre a redefinição da identidade e das políticas públicas de educação...

vens e adultos na hierarquia de prioridades da reforma e da política educacional, fechou o único canal de diálogo então existente com a sociedade civil organizada - a Comissão Nacional de Educação de Jovens e Adultos (CNEJA) - e, por meio do programa Alfabetização Solidária, remeteu para a esfera da filantropia parcela substancial da responsabilidade pública pelo enfrentamento do analfabetismo. ${ }^{15}$

Segmentos sociais politicamente influentes - como as confederações empresariais, as centrais sindicais e a articulação pela educação básica do campo ${ }^{16}$ - encontraram brechas na orientação dominante e conquistaram a abertura, fora do âmbito do Ministério da Educação (MEC), de espaços para formação dos trabalhadores rurais e urbanos, nos programas de Educação na Reforma Agrária (vinculado ao Ministério do Desenvolvimento Agrário) e de Qualificação Profissional (coordenado pelo Ministério do Trabalho e Emprego).

Ainda que tenha renunciado à coordenação interministerial dos programas de educação de jovens e adultos, o MEC não abriu mão de instrumentos de controle e regulação nacionalmente centralizados: regularizou a coleta e divulgação de estatísticas educacionais, criou exames de certificação (Exame Nacional de Certificação de Competências para Jovens e Adultos), instituiu referenciais curriculares, formulou programa de formação (Parâmetros em Ação) e subsidiou a produção de materiais didáticos (Coleção Viver, Aprender). Só tiveram acesso aos recursos do Fundo Nacional de Desenvolvimento da Educação os Estados e municípios que aderiram a essa proposta político-pedagógica.

Pressionado pelos secretários estaduais e municipais de educação e por redes e organizações sociais, o MEC se dispôs a uma cooperação financeira mais substantiva com os governos subnacionais em assuntos relativos à educação de jovens e adultos, instituindo em 2001 o Programa Recomeço, focalizado nos estados do Norte e Nordeste e nos municípios com baixos índices de desenvolvimento humano. Graças aos recursos do Fundo de Combate à Pobreza atribuídos a esse programa, o orçamento federal para a educação de jovens e adultos elevou-se substancialmente, estabelecendo-se desde então em um patamar superior a $\mathrm{R} \$ 340$ milhões anuais.

Empossado em 2003, o governo do presidente Luís Inácio Lula da Silva operou inicialmente uma mudança discursiva, em que a alfabetização de jovens e adultos passou a ser mencionada no rol de prioridades governamentais, ao lado de programas emergenciais de alívio da po- 
breza, como o Fome Zero. Contando com recursos orçamentários limitados e operando com um conceito estreito de alfabetização, a Secretaria Extraordinária de Erradicação do Analfabetismo lançou o programa Brasil Alfabetizado, desenvolvido de modo descentralizado pelos estados, municípios e organizações sociais que a ele aderiram. ${ }^{17}$ Para legitimá-lo, foi convocada uma comissão nacional de caráter consultivo, com participação de representantes da sociedade civil, reabrindo-se assim o diálogo interrompido na década anterior. Dentre os aspectos polêmicos do Programa, destaca-se o desenho assemelhado às campanhas de alfabetização do passado, como a curta duração do módulo de ensino e aprendizagem, ausência de instrumentos de acompanhamento e avaliação, improvisação de alfabetizadores com nenhuma ou escassa formação pedagógica, falta de mecanismos que assegurem aos alfabetizandos a continuidade de estudos e consolidação das aprendizagens.

Se a mudança do discurso teve repercussão positiva no posicionamento da educação de jovens e adultos na agenda política e na cena cultural, a manutenção do sistema de financiamento da educação criado pelo governo anterior limitou seu impacto, restrito também pela dissociação no interior do próprio MEC dos programas de alfabetização e de elevação de escolaridade de jovens e adultos.

Quando, em meados de 2004, ocorreu a troca de ministros da educação, algumas dessas limitações começaram a ser superadas, mediante a reunião dos diferentes programas do MEC na Coordenação de Educação de Jovens e Adultos da Secretaria de Educação Continuada, Alfabetização e Diversidade (SECAD), e a inclusão da modalidade no projeto remetido ao Congresso para o fundo de financiamento da educação básica (FUNDEB), que substituirá o FUNDEF a partir de 2006. Em 2005, a elevação do orçamento e alterações na duração e desenho do Brasil Alfabetizado e Fazendo Escola aumentaram a probabilidade de articulação entre eles, ao mesmo tempo em que a SECAD começou a desenhar instrumentos de diagnóstico, acompanhamento e avaliação desses programas. Após criar o programa Escola de Fábrica, destinado à qualificação profissional em nível básico de estudantes pobres de 16 a 24 anos, a Secretaria de Educação Profissional e Tecnológica também instituiu reserva de vagas para que jovens e adultos cursem o ensino médio e recebam qualificação técnico-profissional na rede federal de educação tecnológica.

$\mathrm{O}$ MEC ainda não foi capaz, porém, de recuperar a coordenação da política interministerial da formação de jovens e adultos, que continua 
Notas sobre a redefinição da identidade e das políticas públicas de educação...

dispersa não só nos ministérios do Trabalho e Emprego (gestor do Plano Nacional de Qualificação) e do Desenvolvimento Agrário (que coordena o PRONERA), mas agora também na recém-criada Secretaria Nacional de Juventude, responsável pelo Pró-Jovem, que sequer se identifica como um programa pertinente à modalidade. ${ }^{18}$ Também não superou o padrão assimétrico adotado pelas gestôes anteriores, pelo qual o governo federal condiciona a cooperação técnica e financeira aos estados, municípios e organizações sociais à adesão incondicional a projetos previamente modelados.

Os desafios indicados pelo movimento por educação de jovens e adultos

A história da educação brasileira nos últimos 50 anos permite que se reconheça a existência de um movimento de educação de adultos, que assumiu diferentes configurações em cada período, mas em todos eles manteve relaçôes de cooperação e conflito com os governos. Desde os anos de 1960, sua influência e participação na execução de políticas públicas foram mais intensas nos períodos de vigência do regime democrático e junto a governos de orientação progressista.

$\mathrm{Na}$ segunda metade da década de 1990 esse movimento se reorganizou para opor resistência à desconstituição dos direitos educativos conquistados na transição democrática. Um marco nesse processo foi a preparação da $\mathrm{V}$ Conferência Internacional de Educação de Adultos (CONFINTEA), realizada pela UNESCO em Hamburgo, em 1997. Convocados pelo MEC por recomendação da Comissão Nacional de Educação de Jovens e Adultos (CNEJA), os seminários preparatórios à V CONFINTEA acirraram as divergências entre os representantes dos diferentes segmentos sociais e as autoridades federais que, adotando um estilo vertical e delegativo de coordenação política, optaram por fechar os canais de diálogo até então existentes.

O movimento adotou, desde então, uma estratégia descentralizada de articulação intersetorial, mediante a constituição nos estados de fóruns de educação de jovens e adultos, que funcionam como espaços públicos de gestão democrática e controle social das políticas educacionais. São espaços abertos, que possuem baixo grau de institucionalidade, têm caráter suprapartidário, reúnem uma pluralidade de organismos go- 
vernamentais e não-governamentais e combinam atividades de informação, formação, mobilização e intervenção.

Os fóruns tomaram para si os compromissos firmados pelo país na V CONFINTEA e, nos anos que a ela se seguiram, utilizaram uma estratégia de articulação em rede para organizar anualmente, em colaboração com instâncias dos três níveis de governo, Encontros Nacionais de Educação de Jovens e Adultos (ENEJAS), quando o movimento tenta influir nas políticas públicas em âmbito nacional.

A primeira das questôes colocadas pelos Fóruns aos dirigentes educacionais refere-se à articulação entre os programas de alfabetização e os níveis mais elevados de escolarização, de modo a garantir aos jovens e adultos a permanência no sistema de ensino e a continuidade de estudos. Por um lado, trata-se da exigência de garantia efetiva do direito ao ensino fundamental público e gratuito, constitucionalmente reconhecido, mas ainda não assegurado. Por outro lado, reflete a adesão ao paradigma da educação continuada ao longo da vida e a uma concepção ampliada de alfabetização que, diante da ampliação das exigências sociais de leitura, escrita e conhecimentos matemáticos, reivindica processos de aprendizagem mais ricos e alongados que, para além dos conhecimentos sobre o funcionamento do sistema de escrita e as técnicas de cálculo, assegurem o letramento, entendido como o desenvolvimento de habilidades, conhecimentos e atitudes que favoreçam o uso desses conhecimentos nas mais diversas práticas sociais (Ribeiro, 2003b; Soares, 1999).

Uma temática recorrente nos fóruns e ENEJAs é aquela do financiamento da educação pública e das políticas de fundos, uma vez que as restrições financeiras impostas pela lógica de focalização são o principal obstáculo para que a prioridade concedida à alfabetização e educação básica de jovens e adultos deixe de ser apenas retórica e possa concretizar-se na ampliação de oportunidades de aprendizagem com qualidade.

Outra questão debatida pelos fóruns e que interroga as políticas públicas é a permanente tensão entre o propósito de inserção orgânica da educação de jovens e adultos nos sistemas de ensino, o que implica o estabelecimento de normas e certo grau de institucionalização, e a necessidade de preservar elevada flexibilidade organizacional, curricular e metodológica para que os programas respondam às necessidades de formação de sujeitos sociais muito diversos.

A formação inicial e continuada de educadores é um dos temas abordados com prioridade pelos fóruns que, convencidos de que a edu- 
Notas sobre a redefinição da identidade e das políticas públicas de educação...

cação de jovens e adultos guarda especificidades relacionadas às identidades e características sociais, psicológicas e culturais dos sujeitos de aprendizagem, há longa data reivindicam espaços e processos próprios de qualificação. A capacitação dos educadores se impõe também pela multiplicidade de agentes sociais envolvidos nos programas de alfabetização e educação de jovens e adultos, muitos dos quais são voluntários ou recrutados nos movimentos populares, sem habilitação profissional formal. As dificuldades de instituição e consolidação de espaços de formação decorrem de múltiplos fatores, como a persistência da visão equivocada que concebe a educação de jovens e adultos como território provisório sempre aberto à improvisação; a precariedade do mercado de trabalho, que não proporciona a construção de carreiras profissionais; e o escasso envolvimento das instituições de ensino superior com um campo educativo de pouco prestígio e baixo grau de formalização.

A agenda de diálogo, reivindicação e conflito dos fóruns com os governos exprime assim, em grande medida, os principais desafios das políticas de educação de jovens e adultos na atualidade.

\section{Recebido e aprovado em setembro de 2005.}

\section{Notas}

1. Referimo-nos, por exemplo, ao Projeto de Educação Básica da Baixada Fluminense que, em 1988, recebeu da UnESCO o Prêmio Nadja K. Kronpskaia (Andrade, 1993); ao Projeto Teimosia da Prefeitura Municipal do Recife (Santos, 1992; Silva, 1994), e ao Movimento de Alfabetização de Adultos criado na gestão de Paulo Freire à frente da Secretaria de Educação de São Paulo (Pontual, 1995; Telles, 1998), dentre outros.

2. Corrente no discurso especializado, a expressão consta nos documentos legais vigentes, a começar pela Constituição Federal de 1988, cujo artigo 208 inscreve dentre os deveres do Estado com a educação a garantia de "ensino fundamental, obrigatório e gratuito, assegurada, inclusive, sua oferta gratuita para todos os que a ele não tiveram acesso na idade própria" (grifo nosso).

3. Vários desses argumentos foram considerados no Parecer 11/2000 do Conselho Nacional de Educação, relatado por Carlos Roberto Jamil Cury, que incorporou a nova concepção de educação de jovens e adultos às normas e diretrizes nacionais da educação básica.

4. As gerações com idade mais avançada são aquelas que sofreram restriçōes de acesso à educação elementar e não puderam beneficiar-se da expansão escolar observada nas últimas décadas. A escassez de oportunidades educacionais daquele período não alcançou igualmente todos os subgrupos sociais dos que hoje são jovens e adultos, atingindo de modo mais acentuado pobres, negros, mulheres, populaçōes rurais e nordestinas. Sobre o assunto, consultar Beltrão \& Novellino (2002), Di Pierro (2001b), Henriques (2001), IBGE 
(2001), MEC (2003), Ramos et al. (2004), Rosemberg \& Piza (1997), Rosemberg (1998), dentre outros.

5. Tratam-se de autores (dentre os quais Alain Touraine, Alberto Mellucci, Anthony Giddens e Manuel Castells) que problematizam a dimensão dialógica da cultura contemporânea e o papel da comunicação intersubjetiva cotidiana nos processos de constituição de identidades coletivas, a emergência de novos atores e movimentos sociais, bem como o associativismo e a conformação de redes como formas privilegiadas de articulação de suas ações (Scherrer-Warren, 1998).

6. Sobre a presença juvenil na educação de jovens e adultos, Haddad et al. (2002) e Sposito et al. (2002) já haviam analisado cerca de quinze títulos, aos quais se somaram novos estudos, mais recentemente, como os de Andrade (2004) e Brunel (2004).

7. Sobre a condição feminina na educação de jovens e adultos, Haddad et al. $(1987,2002)$ localizaram certo número de estudos (Barbosa, 1994; Freitas, 1994; Silva, 1998); posteriormente, encontramos apenas a pesquisa de Nogueira (2002).

8. Damasceno \& Beserra (2004) resenharam recentemente a produção de conhecimento sobre educação rural, registrando numerosos trabalhos relativos à educação de jovens e adultos junto aos movimentos sociais do campo.

9. Embora diversos surveys e relatos de experiência mencionem que as instituiçôes religiosas são importantes agências de letramento (Ribeiro, 2003a, 2003b), localizamos apenas um estudo recente sobre religiosidade e educação de jovens e adultos (Oliveira, 2003).

10. Segundo a PNAD do IBGE, de 2003, o Brasil possuía 14,6 milhões de analfabetos, a maioria dos quais eram negros (67\%), viviam no Nordeste $(54 \%)$ e tinham idades superiores aos 35 anos $(80 \%)$. Apresentando grande variação nos diferentes grupos de renda, localização rural/urbana, regiões, faixas etárias e subgrupos étnico raciais, a escolaridade média dos brasileiros com 25 anos ou mais alcançou 6,3 anos de estudos, abaixo, portanto, dos oito anos de escolaridade que a Constituição Federal de 1988 assegura como direito público subjetivo de todo cidadão.

11. Retomo aqui parte dos argumentos expostos em trabalho anterior de análise das políticas de educação de jovens e adultos da segunda metade dos anos de 1990 (Di Pierro, 2001a).

12. Se as avaliações revelam que numerosos programas de educação básica de adultos apresentam resultados aquém dos esperados, a pesquisa educacional também oferece evidências de que eles podem ser tão ou mais custo-efetivos quanto aqueles proporcionados a crianças e adolescentes. $\mathrm{O}$ método economicista de análise de custo-benefício não é, entretanto, o mais adequado para informar decisões de políticas sociais que afetam direitos universais, como é o caso da educação elementar, pois do ponto de vista ético é inadmissível destituir direitos básicos de um grupo em favor de outro. Além disso, a educação dos dois grupos geracionais não é concorrente, e sim complementar, uma vez que pais e comunidades com maiores níveis educacionais estão mais aptos a valorizar e apoiar a escolarização das novas geraçóes.

13. Para uma descrição e análise dos programas federais de educação de jovens e adultos do período 1996/2002, consultar trabalhos anteriores (Di Pierro, 2001a; 2003; 2004).

14. Criada em 1985 para gerir o legado do Movimento Brasileiro de Alfabetização (MOBRAL), a Fundação Educar coordenou nacionalmente as ações de alfabetização de jovens e adultos no período da redemocratização. Sobre a Fundação, consultar Lovisolo (1988); sobre sua extinção, ver Haddad \& Di Pierro (2000).

15. Criado como política governamental desenvolvida em parceria com empresas e instituições de ensino superior, o programa Alfabetização Solidária nasceu ligado à iniciativa da Co-

Educ. Soc., Campinas, vol. 26, n. 92, p. 1115-1139, Especial - Out. 2005

Disponível em <http://www.cedes.unicamp.br> 
Notas sobre a redefinição da identidade e das políticas públicas de educação...

munidade Solidária da Presidência da República; posteriormente, criou uma sociedade civil sem fins lucrativos para "deslizar" da estrutura administrativa do Estado para a condição de organização não-governamental, com a qual sobreviveu após o término do mandato presidencial.

16. Trata-se de uma articulação interinstitucional da qual participam movimentos sociais do campo, organizações governamentais e não-governamentais, com o apoio da Conferência Nacional dos Bispos do Brasil, da UnesCo, do Unicef e da Universidade de Brasília, que em 1997 realizou a I Conferência Nacional Por uma Educação Básica no Campo, onde se esboçou a proposta do Programa Nacional de Educação na Reforma Agrária (PronerA).

17. O Brasil Alfabetizado visa alfabetizar cerca de 8 milhões de jovens e adultos no período 2003/2007, reduzindo em 50\% o analfabetismo no país. Convênios proporcionam o repasse de recursos do MEC/FNDE para organismos governamentais e não-governamentais para que desenvolvam atividades de formação de alfabetizadores e de alfabetização de jovens e adultos em um período de seis a oito meses. Em 2004, o Programa firmou 382 convênios com secretarias estaduais e municipais de educação, organizações sociais e instituiçôes de ensino superior, destinando R \$ 167 milhôes para que mais de 84 mil educadores alfabetizassem 1,7 milhão de inscritos (Ireland, 2005).

18. Com orçamento de $\mathrm{R} \$ 311$ milhões e meta de alcançar 200 mil jovens em 2005, o Programa Nacional de Inclusão do Jovem (Pró-Jovem) prevê elevação de escolaridade, capacitação profissional, formação para cidadania, distribuição de bolsas de R \$ 100 por mês a jovens de 18 a 24 anos das capitais que estejam fora da escola e do mercado de trabalho e se disponham à ação comunitária. Desenvolvido em parceria com as prefeituras, tem doze meses de duração e prévia definição de currículo, material didático e sistema de certificação.

\title{
Referências bibliográficas
}

\begin{abstract}
ANDRADE, E.R. Nos limites do possivel: uma experiência político-pedagógica na Baixada Fluminense. 1993. Dissertação (Mestrado) - Instituto de Estudos Avançados em Educação, Fundação Getúlio Vargas, Rio de Janeiro.
\end{abstract}

ANDRADE, E.R. A educação de jovens e adultos e os jovens do "último turno": produzindo outsiders. 2004. Tese (Doutorado) - Faculdade de Educação, Universidade Federal Fluminense, Niterói.

ANDRADE, M.R. et al. (Org.). A educação na reforma agrária: uma avaliação do Programa Nacional de Educaçăo na Reforma Agrária. São Paulo: Ação Educativa; Brasília, DF: PRONERA, 2004.

ARELARO, L.R.G.; KRUPPA, S.M. Educação de jovens e adultos. In: OliveirA, R.M.; AdriÃo, T. (Org.). Organização do ensino no Brasil: níveis e modalidades na Constituição Federal e na LDB. São Paulo: Xamã, 2002. p. 89-107. 
ARROYO, M.G. Educação de jovens e adultos: um campo de direitos e de responsabilidade pública. In: Soares, L.J.G.; Giovanetti, M.A.; GoMES, N.L. Diálogos na educação de jovens e adultos. Belo Horizonte: Autêntica, 2005. p. 19-50.

BARBOSA, P.C. Quando Maria aprende a ler Maria: a fala de um grupo de mulheres do Morro do Borel e da Favela de Indiana a respeito da alfabetização. 1994. Dissertação (Mestrado) - Universidade Federal do Rio de Janeiro, Rio de Janeiro.

BEISIEGEL, C.R. A educação de jovens e adultos analfabetos no Brasil. Alfabetização \& Cidadania, São Paulo, n. 16, p. 19-27, jul. 2003.

BELTRÃO, K.; NOVELLINO, M. Alfabetização por raça e sexo no Brasil: evolução no período 1940-2000. Rio de Janeiro: Escola Nacional de Ciências Estatísticas; IBGE, 2002. (Textos para discussão, 1).

BRASIL. Ministério da Educação. Instituto Nacional de Estudos e Pesquisas Educacionais. Mapa do analfabetismo no Brasil. Brasília, DF: MEC/ INEP, 2003.

BRUNEL, C.T.N. Jovens cada vez mais jovens na educação de jovens e adultos. Porto Alegre: Mediação, 2004.

CAMARGO, R.A. A alfabetização de jovens e adultos no município de São Paulo na gestão da prefeita Luiza Erundina de Sousa (1989-1992). 1996. Dissertação (Mestrado) - Pontifícia Universidade Católica de São Paulo, São Paulo.

CORROCHANO, M.C.; NAKANO, M. Jovens, mundo do trabalho e escola. In: Sposito, M.P. (Coord.). Juventude e escolarização (1980-1998). Brasília, DF: MEC/INEP/COMPED, 2002. p. 95-134. (Estado do Conhecimento, 7).

DAMASCENO, M.N; BESERRA, B. Estudos sobre educação rural no Brasil: estado da arte e perspectivas. Educação \& Pesquisa, São Paulo, v. 30, n. 1, p. 73-89, jan./abr. 2004.

DI PIERRO, M.C. Descentralização, focalização e parceria: uma análise das tendências nas políticas públicas de educação de jovens e adultos. Educação \& Pesquisa, São Paulo, v.27, p. 321-338, 2001a.

DI PIERRO, M.C. Políticas públicas y educación de mujeres adultas en 
Notas sobre a redefinição da identidade e das políticas públicas de educação...

Brasil. In: Stromquist, N.; Cortina, R. (Org.). Promoviendo la educación de mujeres y niñas en América Latina. México: Pax, 2001b. p. 43-74.

DI PIERRO, M.C. (Coord.) Seis anos de educação de jovens e adultos no Brasil. São Paulo: Ação Educativa, 2003.

DI PIERRO, M.C. Um balanço da evolução recente da educação de jovens e adultos no Brasil. Alfabetização \& cidadania, São Paulo, v. 17, p.11-23, 2004.

FREITAS, J.R. Alunos e alunas da classe trabalhadora na escola noturna: obediência e resistência. 1994. Dissertação (Mestrado) - Pontifícia Universidade Católica do Rio Grande do Sul, Porto Alegre.

GALVÃO, A.; SOARES, L. História da alfabetização de adultos no Brasil. In: Albuquerque, E.; Leal, T. (Org.) A alfabetização de jovens e adultos em uma perspectiva de letramento. Belo Horizonte: Autêntica, 2004.

GOHN, M.G. Movimentos sociais e educação. 6. ed. São Paulo: Cortez, 2004.

HADDAD, S. (Coord.). Ensino supletivo no Brasil: o estado da arte. Brasília, DF: REDUC, 1987.

HADDAD, S. (Coord.). Educação de jovens e adultos no Brasil (19861998). Brasília, DF: MEC/INEP/COMPED, 2002. (Estado do Conhecimento, 8).

HADDAD, S.; DI PIERRO, M.C. Escolarização de jovens e adultos. Revista Brasileira de Educação, São Paulo, n. 14, p. 108-130, maio/ago. 2000 .

HENRIQUES, R. Educação: herança e horizontes da discriminação educacional. In: HenriQues, R. et al. Desigualdade racial no Brasil: evolução das condições de vida na década de 90. Rio de Janeiro: IPEA, 2001. (Textos para discussão, 807).

INSTITUTO BRASILEIRO DE GEOGRAFIA E ESTATISTICA (IBGE). Censo demográfico 2000: educação; resultados da amostra. Rio de Janeiro: IBGE, 2003.

IRELAND, T. Perfil de país para iniciativa da UNESCO para alfabetização "Saber para poder". Brasília, DF: MEC/SECAD/DEJA, 2005. 
IRELAND, T.; MACHADO, M.M.; PAIVA, J. (Org.). Educação de jovens e adultos: uma memória contemporânea (1996-2004). Brasília, DF: UNESCO/MEC, 2004.

LOVISOLO, H. A educação de adultos entre dois modelos. Cadernos de Pesquisa, São Paulo, n. 67, p. 23-40, 1988.

NOGUEIRA, V.L. Mulheres adultas das camadas populares: a especificidade da condição feminina na busca da escolarização. 2002. Dissertação (Mestrado) - Universidade Federal de Minas Gerais, Belo Horizonte.

OLIVEIRA, H.S. Escola noturna e jovens: relação entre religiosidade e escolarização. In: SoAres, L.J.G. Aprendendo com a diferença: estudos e pesquisas em educação de jovens e adultos. Belo Horizonte: Autêntica, 2003.

OLIVEIRA, M.K. Jovens e adultos como sujeitos de conhecimento e aprendizagem. Revista Brasileira de Educação, São Paulo, v. 12, p. 59-73, 1999.

PASSOS, J.C. A escola no projeto de vida dos/as jovens negros/as que freqüentam a Educação de Jovens e Adultos em Florianópolis. Florianópolis, 2004 (relatório de pesquisa).

PONTUAL, P.C. Desafios pedagógicos na construção de uma relação de parceria entre movimentos populares e o governo municipal da cidade de São Paulo na gestão Luiza Erundina: a experiência do MOVA-SP. 1995. Dissertação (Mestrado) - Pontifícia Universidade Católica de São Paulo, São Paulo.

RAMOS, M.N.; MOREIRA, T.M.; SANTOS, C.A. (Coord.). Referências para uma política nacional de educação do campo: caderno de subsídios. Brasília, DF: SEMT/GPTEC/MEC, 2004.

RIBEIRO, V.M. Para ler as políticas e práticas de leitura no Brasil. In: POLITICAS e práticas de leitura no Brasil. São Paulo: Ação Educativa, 2003a, p. 12-17. (Em Questão, 2).

RIBEIRO, V.M. (Org.). Letramento no Brasil. São Paulo: Global, 2003 b.

ROSEMBERG, F. Raça e desigualdade educacional no Brasil. In: Aquino, J.G. (Coord.). Diferenças e preconceito na escola: alternativas teóricas e práticas. São Paulo: Summus, 1998. p. 73-91. 
Notas sobre a redefinição da identidade e das políticas públicas de educação...

ROSEMBERG, F; PIZA, E. Analfabetismo, gênero e raça no Brasil. In: Bógus, L.; Paulino, Y. (Org.). Políticas de emprego, políticas de população e direitos sociais. São Paulo: EDUC, 1997.

SANTOS, M.H.S. Educação de jovens e adultos: estudo de um projeto político-pedagógico popular. 1992. Dissertação (mestrado) - Universidade Federal de Pernambuco, Recife.

SCHERER-WARREN, I. Movimentos em cena: ... e as teorias por onde andam? Revista Brasileira de Educação, São Paulo, n. 9, p. 21, 1998.

SILVA, C.A. Explorando novos caminhos para a democracia: os desafios da participação popular na gestão pública e o Movimento de Alfabetização de Jovens e Adultos da cidade de São Paulo (MOVA). 1998. Dissertação (mestrado) - Instituto de Filosofia e Ciências Humanas, Universidade Estadual de Campinas, Campinas.

SILVA, E.L. Gênero, alfabetização e cidadania: para além das habilidades de leitura e escrita. 1998. Dissertação (Mestrado) - Universidade Federal da Paraíba, João Pessoa.

SILVA, S.M.C. O coletivo de projetos populares de educação de jovens e adultos: a experiência de sua articulação e organização durante a gestão popular do Recife (1985-1988). 1994. Dissertação (Mestrado) - Universidade Federal da Paraíba, João Pessoa.

SOARES, L.J.G. O surgimento dos Fóruns de EJA no Brasil: articular, socializar e intervir. Alfabetização \& Cidadania, São Paulo, n. 17, p. 2535, maio 2004.

SOARES, M.B. Letramento: um tema em três gêneros. Belo Horizonte: Autêntica, 1999.

SPOSITO, M.P. Algumas hipóteses sobre as relações entre movimentos sociais, juventude e educação. Revista Brasileira de Educação, São Paulo, n. 13, p. 73-91, jan./abr. 2000.

SPOSITO, M.P. (Coord.) Juventude e escolarização (1980-1998). Brasília, DF: MEC/INEP/COMPED, 2002. (Estado do Conhecimento, 7).

TELLES, S.A.S. Todo ser humano tem condiçôes de construir conhecimento: uma experiência de formação de educadores em parceria entre movimen- 
tos populares e o governo municipal da cidade de São Paulo: Mova-SP, 1989-1992. 1998. Dissertação (Mestrado) - Universidade Federal Fluminense, Niterói.

TORRES, R.M. Aprendizaje a lo largo de la vida. Educación de Adultos y Desarrollo, Bonn, supl. 60, 2003. 